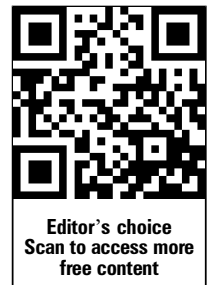

${ }^{1}$ Academic Department of Military Emergency Medicine, Royal Centre for Defence Medicine, Birmingham, UK ${ }^{2}$ Forensic Pathology Services, Wantage, Oxon, UK ${ }^{3}$ South West Group Practice, Bristol, UK

\section{Correspondence to} Col R J Russell, Academic Department of Military Emergency Medicine, Institute of Research and Development, Birmingham Research Park, Vincent Drive, Birmingham B15 2SQ, UK;

Prof.ADMEM@rcdm.bham.ac.uk

Received 29 November 2013 Revised 17 December 2013 Accepted 10 January 2014 Published Online First 25 February 2014

\title{
The Mortality Peer Review Panel: a report on the deaths on operations of UK Service personnel 2002-2013
}

\author{
Robert Russell, ${ }^{1} \mathrm{~N} \mathrm{Hunt}^{2}{ }^{2}$ R Delaney ${ }^{3}$
}

\begin{abstract}
Introduction Review of adverse outcomes is an essential element of healthcare governance. For each operational death, the post-mortem is attended by a member of Academic Department of Military Emergency Medicine and the case is assessed by a Mortality Peer Review Panel comprised of Defence Professors and other clinical and technical experts.

Methods A search was conducted of the Joint Theatre Trauma Registry (JTTR) for all UK military death reviews

\section{Key messages}

All UK military deaths on operations are reviewed by a multidisciplinary panel.

- $55.65 \%$ were due to blast and $28.71 \%$ due to gunshot wounds.

- $91.1 \%$ were judged not salvage-able by the panel.
\end{abstract} held from January 2002 to November 2013 and the judgement made by the Mortality Peer Review panel. Cases are awarded a 'salvageability' rating between S1 (salvageable) and S4 (not salvageable). Cases graded S1-3 are then assessed further for tactical, clinical or equipment factors that affected the outcome.

Results There were 621 deaths recorded on the JTTR and $517(83.3 \%)$ were due to hostile action. The Killed in Action to Died of Wounds ratio is 6.28:1. Explosive mechanisms of injury were responsible for $55.65 \%$ of combat deaths and penetrating mechanisms $28.71 \%$. An average of 10.56 injuries was recorded per casualty and the mean number of body regions affected was 3.34. The Peer Review Panel decided that $91.1 \%$ cases were not salvageable (S4); this figure is $93.5 \%$ if the deaths due to hostile action are considered separately.

Conclusions The severity of modern military trauma is overwhelming in nature and, along with trauma scoring systems, clinical peer review is an essential part of healthcare governance. The process also helps inform and direct research within clinical and force protection fields.

\section{INTRODUCTION}

Healthcare Governance is a central function within the Defence Medical Services (DMS). ${ }^{1-4}$ Assuring optimal performance of the DMS operational trauma system is an important contribution to the moral effect for troops, families and the public. In the assessment of the performance of any trauma system, a review of adverse outcomes is essential. ${ }^{45}$

The UK Joint Theatre Trauma Registry (JTTR), maintained by the Academic Department of Military Emergency Medicine (ADMEM) at the Royal Centre for Defence Medicine (RCDM) and Defence Statistics (Health), is a prospective trauma database that collects information on all casualties admitted to UK deployed military hospitals as the result of a trauma call or who are evacuated back to the 'Role 4' base hospital at Queen Elizabeth Hospital, Birmingham, as a result of trauma. Consequentially, JTTR holds data on all UK military deaths resulting from operations and exercises abroad. Details are collected from clinical notes, post-mortem reports and incident reports and a member of ADMEM attends all military postmortems to prevent the loss of potentially important medical intelligence ${ }^{67}$ and provides appropriate feedback to the theatre of operations as soon as possible via the Defence Professor Emergency Medicine. This clinical presence also ensures that the military and medical contexts can be clarified to the pathologists and other experts present to monitor personal and vehicle protective equipment effectiveness.

In addition to the initial evaluation, the Military Mortality Peer Review Panel meets two or three times a year to provide senior multidisciplinary review of deaths in the intervening periods. The Panel (Box 1) first met in late 2006 and reported in 2008 on 12 months from 1 April $2006^{8}$ and is currently convened and chaired by the Defence Professor Emergency Medicine. This paper describes the patterns of UK Service deaths and results from the panel meetings.

Box 1 Members of the Military Mortality Review Panel

Defence Professor of Anaesthetics and Critical Care

- Defence Professor of Surgery

- Defence Professor of Orthopaedics and Trauma

- Home Office Pathologists

- Senior Scientist, Dstl Porton Down

- Senior Consultant Critical Care, Queen Elizabeth Hospital Birmingham

- Senior Nursing Officer RCDM, Queen Elizabeth Hospital Birmingham

- Representative from Inspector General DMS DMS, Defence Medical Services; Dstl, Defence Science and Technology Laboratories; RCDM, Royal Centre for Defence Medicine. 


\section{METHODS}

A search was conducted of JTTR for all UK military deaths from January 2002 to November 2013 and the judgement made by the Mortality Peer Review panel. The panel reviews each case using a description of the mechanism of injury, evacuation timelines, injuries sustained and procedures undergone at each location. A summary including trauma scoring results is given for each case and the clinical notes, post-mortem reports and incident details are also available.

Salvageability is determined first in each case (Box 2); if a case is rated as non-survivable (S4) then further analysis is not recorded but if there are lessons identified, they are flagged up in the relevant channels. However, in other cases, discussion as to the factors affecting survival takes place. These factors are grouped into Tactical, Equipment and Clinical categories and a brief description of each factor and its impact is recorded if appropriate. This latter process replaced a further rating, which was given as to preventability until 2010 as it allowed more detail to be recorded and similar cases grouped together if necessary.

For cases reported in this paper prior to the start of the review panel process in 2006, an initial sifting process of all deaths from 2002 was undertaken by the Defence Professor Emergency Medicine. Cases that were clearly S4 (eg, decapitation, whole body disruption) were recorded on JTTR as such and only those in which salvage was thought possible or where there was doubt as to the grading were brought to the panel.

\section{RESULTS}

JTTR holds the records of 621 deaths dating from 2002. The Army accounted for 500 (80.5\%), Royal Marines 70 (11.3\%), Royal Air Force 43 (6.9\%) and Royal Navy 8 (1.3\%); 611/621 (98.4\%) were male personnel. The age range was $18-51$ with a mean of 26.7 years. The definitions and distributions of casualty categories are shown in Figure 1 and Box 3. The ratio of killed to died overall was $6.48: 1$, but if hostile action (HA) only is included, the ratio is $6.28: 1$.

Cases are shown by year and theatre of operation and then by Operation and roulement (Table 1). The mechanisms of injury for the 620 cases for which it been determined at the time of writing are demonstrated in Figure 2. Explosive mechanisms produced $345(55.65 \%)$ and penetrating 178 (28.71\%).

\section{Box 2 Definitions of salvageability}

Salvageability: 'If these injuries had occurred 5 minutes from a Major Trauma Centre what is the likelihood that surgical intervention would be attempted for given injuries and the predicted influence on survival':

- S1: Salvageable: intervention would likely have influenced survival (probability of survival $>95 \%$ ).

- S2: Potentially salvageable: intervention would have been attempted and may have influenced survival (probability of survival 5\%-95\%).

- S3: Possibly salvageable: intervention would have been attempted but with a high probability of mortality (probability of death $>95 \%$ ).

S4: Non-salvageable: intervention would not have led to survival.

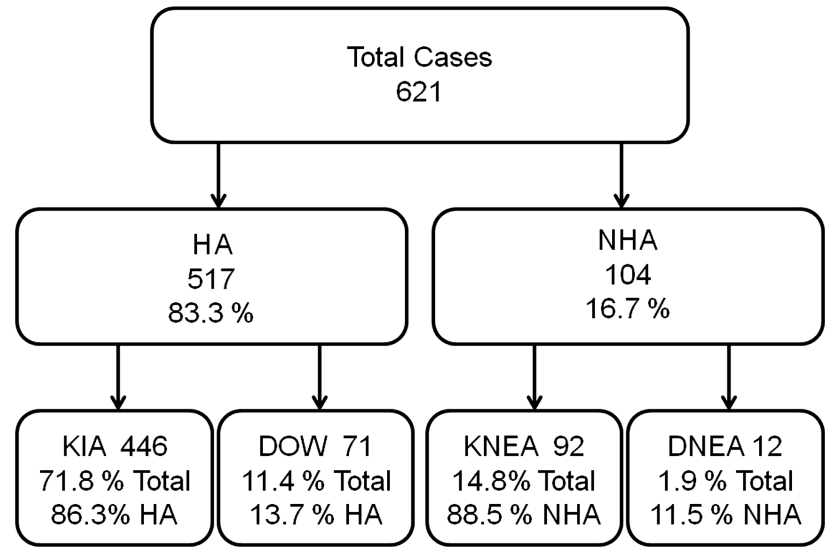

Figure 1 Casualty category distributions. DNEA, died from nonenemy action; DOW, died of wounds; HA, hostile action; KIA, killed in action; KNEA, killed by non-enemy action; NHA, non-hostile action.

\section{Injury scoring}

Injury Severity Scores (ISS) ${ }^{9}$ ranged between 4 and 75 with a median score of 75 and an IQR of $57-75 ; 21$ did not have a score recorded. Three cases had an ISS below15, 164 were in the range 16-59 and 454 had a score of 60-75, which has been defined as 'un-survivable trauma'. The New Injury Severity Score ${ }^{10}$ showed similar results but with an IQR of 75-75.

The Triage Revised Injury Severity Score (TRISS) ${ }^{11}$ and A Severity Characterisation of Trauma (ASCOT) ${ }^{12}$ values could be calculated for 559 deaths as physiological data were missing in the other 62 cases. For TRISS, eight had a probability of survival $>50 \%$, this being the cut-off between 'expected' and 'unexpected deaths' whereas ASCOT, which uses a calculated $<50 \%$ percentage chance of death as a similar cut-off, had 16 in this category.

The total number of recorded injuries ranged from 1 to 57 with an average of 10.56 per casualty. The Abbreviated Injury Scale (AIS) ${ }^{13}$ body regions injured per casualty ranged between 1 and 9 (all) with the mean number of regions injured being 3.34 and the median 3 (IQR 2-5) (Table 2 and Figure 3).

\section{Salvageability}

Overall, 617 cases had a recorded salvageability judgement by the Peer Review Panel (Table 3), two cases are awaiting consideration and two cases do not have enough information on injuries

\section{Box 3 Casualty category definitions}

KIA (Killed in Action): personnel killed instantly or dying before reaching a UK or a coalition ally medical treatment facility as a result of hostile action.

- DOW (Died of Wounds): personnel who die as a result of injuries inflicted by hostile action after reaching a UK or coalition ally medical treatment facility.

- KNEA (Killed by Non-Enemy Action): personnel killed instantly or before reaching a UK or a coalition ally medical treatment facility as a result of non-hostile activity.

- DNEA (Died from Non-Enemy Action): personnel who die as a result of injuries caused by non-hostile activity after reaching a UK or coalition ally medical treatment facility. 
and medical treatment to form a considered opinion and both occurred outside the usual UK DMS medical chain.

One of the three 'definitely salvageable' casualties died as tactical issues prevented medical aid reaching him. In both the other cases, treatment issues were thought to play a part (poor application of tourniquets, failure to call a trauma team, possible over-administration of opiates and poor handling of massive transfusion and hypothermia). The factors affecting the S2 cases were tactical in nine, military equipment in one and treatment

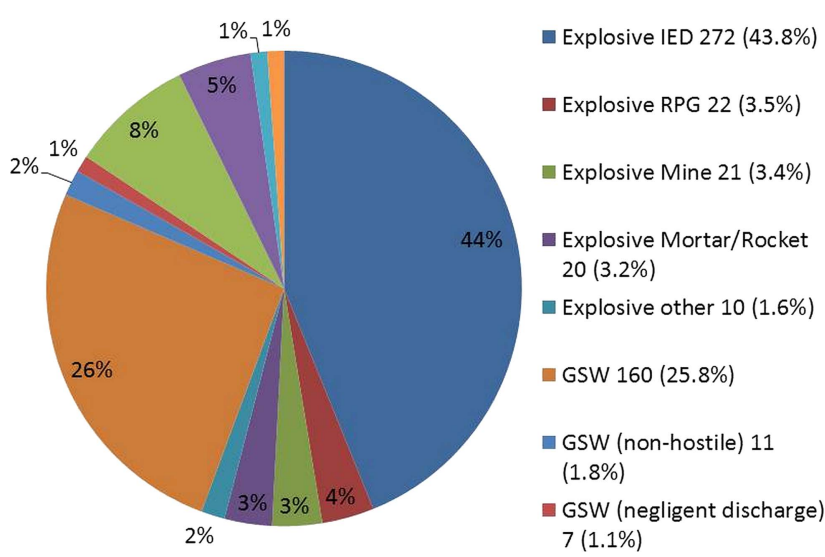

Figure 2 Mechanism of injury.

in four (tourniquet application, incorrect drain site and development of complications). In one S3 case, a single aspect of treatment (tourniquet application) could have been improved but it would be unlikely to have produced a different outcome. In total, 24 cases were affected by tactical considerations and in the remaining 10 it was considered that everything possible had been done and that while survival was possible, it would be extremely unlikely in even the best circumstances (percentage chance of survival $<5 \%$ ).

\section{DISCUSSION}

The Peer Review Panel is an important part of providing assurance to the Chain of Command that the DMS Trauma system is functioning optimally and that Healthcare Governance of the system is in place in that continuous adjustments and improvements are made. As well as immediate feedback to theatre following a post-mortem, comments are passed to clinicians through the Deployed Medical Director (DMD) and at the weekly Joint Theatre Clinical Conference. Feedback can also be passed from the DMD to the Medical Regiment and thus to the Combat Medical Technicians who dealt with the casualty at the point of wounding. This also allows everyone involved in a casualty's care the opportunity to raise questions and receive answers about what happened. Where there has been deviation from standardised procedures, explanations are sought that may result in identification of a training gap and appropriate measures taken.

Table 2 Number of injuries by body region and Anatomic Injury Scores (AIS)

\begin{tabular}{|c|c|c|c|c|c|c|c|c|c|}
\hline \multirow[b]{2}{*}{ Body region } & \multirow{2}{*}{$\begin{array}{l}\text { Number of cases } \\
\text { with highest AIS in } \\
\text { region }\end{array}$} & \multirow{2}{*}{$\begin{array}{l}\text { Number of cases } \\
\text { with injury in } \\
\text { region }\end{array}$} & \multirow[b]{2}{*}{$\begin{array}{l}\text { Maximum (mean) } \\
\text { number of injuries }\end{array}$} & \multicolumn{6}{|c|}{ Number of cases with a maximum given AIS in each region } \\
\hline & & & & $\begin{array}{l}\text { AIS } 6 \\
\text { (Fatal) }\end{array}$ & $\begin{array}{l}\text { AIS } 5 \\
\text { (Critical) }\end{array}$ & $\begin{array}{l}\text { AIS } 4 \\
\text { (Severe) }\end{array}$ & $\begin{array}{l}\text { AIS } 3 \\
\text { (Serious) }\end{array}$ & $\begin{array}{l}\text { AIS } 2 \\
\text { (Moderate) }\end{array}$ & $\begin{array}{l}\text { AIS } 1 \\
\text { (Minor) }\end{array}$ \\
\hline Head & 249 & 321 & $18(3.32)$ & 220 & 44 & 19 & 0 & 2 & 4 \\
\hline Face & 2 & 208 & 8 (1.94) & 0 & 18 & 14 & 10 & 86 & 80 \\
\hline Neck & 43 & 155 & $7(2.03)$ & 22 & 58 & 18 & 3 & 37 & 6 \\
\hline Spine & 18 & 179 & 11 (1.98) & 47 & 21 & 13 & 14 & 85 & 0 \\
\hline Thorax & 99 & 273 & 19 (3.78) & 108 & 58 & 91 & 62 & 22 & 7 \\
\hline Abdomen & 39 & 342 & $15(3.97)$ & 14 & 76 & 86 & 45 & 47 & 11 \\
\hline Upper extremity & 3 & 242 & $12(2.13)$ & 0 & 3 & 54 & 63 & 101 & 21 \\
\hline Pelvis and legs & 53 & 348 & $12(3.55)$ & 0 & 139 & 56 & 51 & 14 & 12 \\
\hline External & 27 & 75 & $5(1.22)$ & 37 & 1 & 1 & 3 & 3 & 30 \\
\hline
\end{tabular}




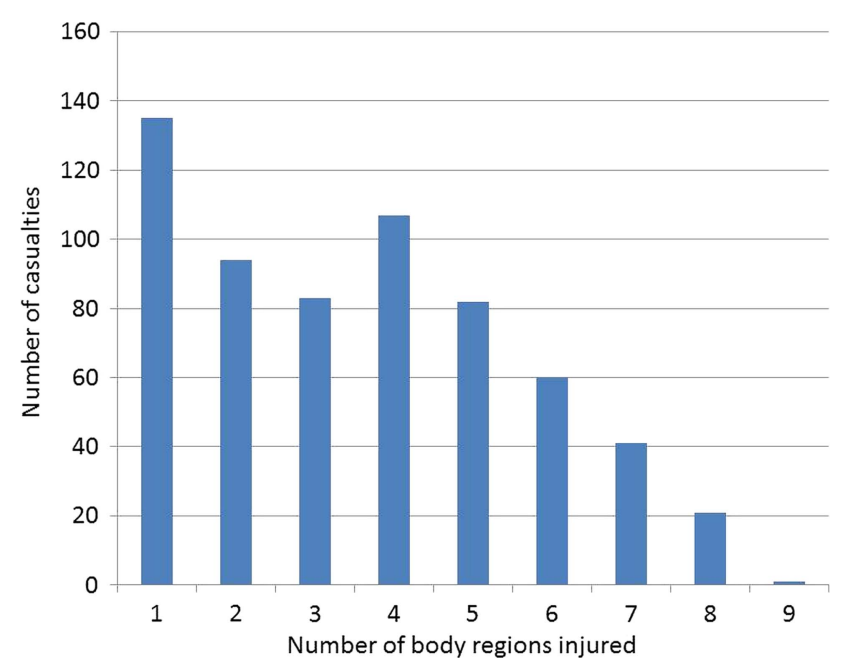

Figure 3 Distribution of number of Abbreviated Injury Scale body regions injured.

Further benefits derived from the in-depth review of military operational mortality have been the increased linkages between clinical personnel and those working for other Defence agencies. The review has been used to determine emerging injury and treatment patterns, determine potential areas of clinical research and inform the on-going development of personal and vehicular protective systems and equipment.

There is a potential overlap in the definitions of Killed in Action (KIA) and Died of Wounds (DOW) that are duplicated for Killed by Non-Enemy Action and Died from Non-Enemy Action. Depending on circumstances, a casualty who arrives at hospital in cardiac arrest may receive blood and undergo surgery before resuscitation attempts are ceased and death pronounced. The convention that has been applied in these cases is that if there have been any signs of life at any time after arrival at the hospital then DOW is used, otherwise KIA is the designation. There are 32 cases who received blood in the emergency department and/or theatre but as they did not regain a cardiac output at any stage, are still classified as KIA. In one case, nine units of packed red blood cells and five units of fresh frozen plasma were given. This case and 28 others were S4 when reviewed. The two S2 and five S3 cases all had prolonged evacuation periods as a result of tactical issues. The S4 cases potentially represent failure to recognise futility. In the resource-rich environment of Bastion Role 3, this may not have further ramifications if there are no other casualties requiring immediate treatment. However, as the Armed Forces move to contingency operations, resources will be much more limited. While the final decision to stop resuscitative efforts should always rest with the clinicians at the trolley-side, a further study of these cases will be undertaken to determine if lessons can be drawn and if there is any potential for 'rules of thumb' to be developed.

Comparison with the experience of American Forces described by Eastridge $e t a l^{5}$ is interesting but no firm conclusions can be drawn as there has been no cross-review or communication on this subject between the reviewers and parameters may have differed. The KIA to DOW ratios of HA casualties are very similar (UK 6.28 vs US 6.87) but the UK review panel rated $93.5 \%$ (416 cases) of HA casualties non-salvageable compared with the US figure of $75.7 \%$ rated non-survivable. There are many potential explanations for this difference not least a different application of the cut-off between KIA and DOW as described above. The KIA to DOW ratio has in the past been suggested as a measurement of trauma system performance but 'inevitable' deaths surviving to reach hospital before dying make it a poorer tool than identifying unexpected outcomes. ${ }^{8}$

The results of this paper point to the overwhelming severity and nature of military trauma described in other studies ${ }^{14} 15$ especially given the proportion of injuries caused by improvised explosive devices. Data from the Vietnam War and previous modern conflicts showed a preponderance of single lifethreatening injuries. ${ }^{16}$ In the battlefield environment, any AIS score 4 or greater is potentially fatal. ${ }^{17}$ In this study, 371 cases had AIS $4+$ injuries to more than one body region, the highest being six regions, and 80 had AIS 6 injuries to two or more regions (highest 4). Of those killed by an AIS $4+$ injury to a single body region, the head (72 cases) and thorax (46) were most often involved.

A further finding is the necessity to apply a clinical dimension to the review process as well as using the different trauma scoring methods especially when considering individual cases. As was observed when analysing survivors over 18 months between 2006 and $2008,{ }^{4}$ there is not necessarily agreement between the methods themselves or between them and experienced clinical opinion. In total, 17 cases were identified by ASCOT and/or TRISS as 'expected survivors' (one TRISS only, eight ASCOT only and eight by both). Of these, clinical review

\begin{tabular}{|c|c|c|c|c|c|c|}
\hline & S1 Definite & S2 Potential $(>5 \%,<95 \%)$ & S3 Possible $(<5 \%)$ & S4 (Not salvageable) & Outstanding/not rated & Total \\
\hline 2002 & - & - & - & 3 & - & 3 \\
\hline 2003 & 1 & - & - & 47 & - & 48 \\
\hline 2004 & - & 1 & - & 22 & - & 23 \\
\hline 2005 & - & - & - & 24 & - & 24 \\
\hline 2006 & - & 1 & 1 & 66 & 1 & 69 \\
\hline 2007 & 1 & 2 & 6 & 80 & - & 89 \\
\hline 2008 & - & 3 & 3 & 49 & - & 55 \\
\hline 2009 & 1 & 4 & 14 & 90 & - & 109 \\
\hline 2010 & - & 2 & 6 & 96 & - & 104 \\
\hline 2011 & - & - & 2 & 43 & 1 & 46 \\
\hline 2012 & - & - & 3 & 39 & - & 42 \\
\hline 2013 (to November) & - & - & - & 7 & 2 & 9 \\
\hline Total & $3(0.5 \%)$ & 13 (2.1\%) & 35 (5.6\%) & 556 (91.1\%) & $4(0.6 \%)$ & 621 \\
\hline
\end{tabular}


graded 10 as S4, three S3, one S2 and two S1; three further cases had an ISS of $<15$ thus not reaching the threshold for 'major trauma'. All three were expected deaths on TRISS and ASCOT due to their physiological status on arrival at hospital and peer review award one each to S2, S3 and S4. In all three, tactical aspects caused a delayed evacuation.

The members of the review panel have not been identical throughout the period of this paper due in particular to deployments. This is a source of weakness but it is also a potential strength as it has meant that all the military members of the panel have had recent operational experience. Regardless, the membership has been relatively stable with the personnel listed in acknowledgements attending over two-thirds of meetings and three of whom have attended all but one or two. Judgements have as a result been consistent to the standard of the best practice available at the time of that particular meeting. However, over time the parameters within which those judgements have been made have been shifting on a regular basis as advances in trauma treatment in the DMS developed. An injury pattern illustrating this is multiple amputations following an improvised explosive device strike. This has been the signature injury pattern of Op HERRICK and, when first seen in the meetings, survival was thought to be unlikely. As the DMS experience has developed along with training, equipment and techniques, good outcomes have been achieved on a regular basis and scrutiny of cases reaching the mortality meeting is intense.

A further study of the DOW cases dying at the UK Role 4 is in progress to determine if there are any specific lessons to be learnt from this sub-group. A similar project is also ongoing into 'unexpected survivors' over a longer period than described previously. ${ }^{4}$ While tactical issues were the most common factor identified in the cases graded S1-3 and each case has been examined individually, a more in-depth study of the group is required as a whole to identify if there are any key learning points that may inform clinical practice or force protection.

\section{CONCLUSIONS}

Mortality Peer Review has identified that $91.1 \%$ of UK military operational deaths since 2002 were the result of non-survivable trauma. For casualties categorised as KIA, this figure is $93.5 \%$. While trauma scoring systems are useful tools, clinical peer review is an essential part of the robust healthcare governance process that is in place to identify potential lessons and give feedback.
Acknowledgements The following have been regular members of the peer review panel: Surg Capt M Midwinter; Col J Clasper, Col P Mahoney, Col R Russell, Dr A Hepper, Dr R Delaney, Dr N Hunt and Dr P Wood. The authors thank the staff of the Joint Theatre Trauma Registry, ADMEM who attended post-mortems and collected data on casualties as well as putting the meetings together.

Contributors RR planned, conducted and reported the study and is the guarantor of the content. $\mathrm{NH}$ and $\mathrm{RD}$ contributed to the review process and the writing of the manuscript.

Competing interests None.

Provenance and peer review Not commissioned; externally peer reviewed.

\section{REFERENCES}

1 Hodgetts TJ, Davies S, Russell RJ, et al. Benchmarking the UK military deployed trauma system. J R Army Med Corps 2007;153:237-8.

2 Smith J, Hodgetts TJ, Mahoney PF, et al. Trauma Governance in the UK Defence Medical Services. J R Army Med Corps 2007;153:239-42.

3 Healthcare Commission. Defence Medical Services: a review of the clinical governance of the Defence Medical Services in the UK and overseas. London, 2009.

4 Russell RJ, Hodgetts TJ, McLeod J, et al. The role of trauma scoring in developing trauma clinical governance in the Defence Medical Services. Philos Trans $R$ Soc Lond B Biol Sci 2011;366:171.

5 Eastridge BJ, Mabry RL, Seguin P, et al. Death on the battlefield (2001-2011): implications for the future of combat casualty care. J Trauma Acute Care Surg 2012;73:S431-7

6 Marx WH, Simon HM, Jumbelic M, et al. Severity of injury is underestimated in the absence of autopsy verification. J Trauma 2004;57:46-50.

7 Sharma BR, Gupta M, Harish D, et al. Missed diagnoses in trauma patient vis-à-vis significance of autopsy. Injury 2005;36:976-83.

8 Hodgetts TJ, Davies S, Midwinter M, et al. Operational mortality of UK Service personnel in Iraq and Afghanistan: a one year analysis 2006-7. J R Army Med Corps 2007;153:252-4.

9 Baker SP, O'Neill B, Haddon W, et al. The injury severity score: a method of describing patients with multiple injuries and evaluating emergency care. J Trauma 1974;14:187-96

10 Osler T, Baker S, Long W. A modification of the Injury Severity Score that both improves accuracy and simplifies scoring. J Trauma 1997;43:922-6.

11 Boyd CR, Tolson MA, Copes WS. Evaluating trauma care: the TRISS method. J Trauma 1987;27:370-8

12 Champion HR, Copes WS, Sacco WJ, et al. A new characterisation of injury severity. J Trauma 1990;30:539-46.

13 Association for the Advancement of Automotive Medicine. Abbreviated Injury Scale 2005. Barrington, Illinois, 2005.

14 Singleton JAG, Gibb IE, Hunt NCA, et al. Identifying future 'unexpected' survivors: a retrospective cohort study of fatal injury patterns in victims of improvised explosive devices. BMJ Open 2013:3:e003130.

15 Ramasamy A, Harrisson SE, Clasper JC, et al. Injuries from roadside improvised explosive devices. J Trauma 2008:65:910-14.

16 Bellamy RF. The causes of death in conventional land warfare: implications for combat casualty care research. Mil Med 1984;149:55-62.

17 Champion HR, Holcomb JB, Lawnick MM, et al. Improved characterization of combat injury. J Trauma 2010;68:1139-50. 